\title{
Transfer Pricing Model of Highway Operation Rights Based on Cooperative Game in TOT Mode
}

\author{
Wang-Ruijing $^{1, a^{*}}$, Fang-Yong ${ }^{2, b}$, Li-Mingshun ${ }^{3, c}$ \\ ${ }^{1,2,3}$ School of Traffic and Transportation Engineering, Changsha University of Science \& Technology, \\ Changsha, 410114, China \\ a *email: wrjing2014@163.com, bemail: 406235509@qq.com, \\ cemail:279571178@qq.com
}

\section{Keywords: Highway Operation Rights TOT Mode Value Assessment Cooperative Game}

\begin{abstract}
In essence, transfer pricing of highway operation rights in TOT mode is the result of the cooperative game between the government and investors, the purpose of which is to achieve a win-win situation. Aimed at characteristics of highway construction project in TOT mode, the paper analyzed the formation of the relationship of cooperative game between the government and investors and defined the related elements of cooperative game about the negotiation course of transfer pricing of highway operation rights, then to build cooperative game model and use Robin Stein bargaining game solution to solve the model.
\end{abstract}

\section{Introduction}

With the country's economic system reform deepening and market economy sustainably developing, project financing is inevitably becoming increasingly difficult. To solve this problem, it is necessary to broaden the financing channels of the project, and then the TOT (Transfer-Operate-Transfer) project financing mode is becoming an effective way to promote China's highway construction. Local government applies TOT financing mode to transfer operation rights of the existing highway assets and by this way, it is not only raising the funds for investment needing in next step highway construction but introducing advanced technology and management method which has an important role in promoting high-efficiency operation of the running project.

TOT project financing ${ }^{[1]}$ (Transfer -Operation -Transfer) is a new financing way by selling existing assets in order to obtain incremental funds for new project financing. This approach is also an effective pattern of using private capital operating infrastructure project. Concession Operation is a way of private capital to participate in the operation of highway projects which main purpose is profit. The transfer price of highway operation rights has become an important factor in affecting whether it would be profitable and the level of profit, which determined if TOT financing project can be proceed smoothly ${ }^{[2,3]}$. It is worth exploring how to obtain a win-win transfer pricing in a mutually satisfactory situation.

The paper scientifically and systematically studied the transfer pricing formula ${ }^{[4]}$ with the help of cooperative game theory in TOT mode and meanwhile, drew the investors' minimum expect benefit formula, which has a practical significance in whether both government and investors could reach an agreement in the cooperation of highway project in TOT financing mode. 


\section{The game analysis of the transfer of highway operation rights in TOT mode}

The formation of the relationship of cooperative game between the government and investors. The different goals between the government and the investors in TOT mode lead to the formation of the relationship of cooperative game between two sides. In the view of whole economy society, the government considered factors from the politics, economy, society and other factors. By contrast, investors usually take the maximum economic benefits as its goal. Therefore, the relationship of the cooperative game between two sides in TOT mode is formed because of different goals. The cooperation foundation of both sides in TOT mode is the common goals ${ }^{[5]}$. However, there are differences between the goal, for example the government hopes to obtained more financing funds to continue re-investment in the field of highway while the investors hope to obtain higher returns with less investment. So the conflicting differential goal between two sides enables the relationship of cooperative game to be formed. As is shown in Figure 1, it is the intersection of goal between two sides in TOT mode.

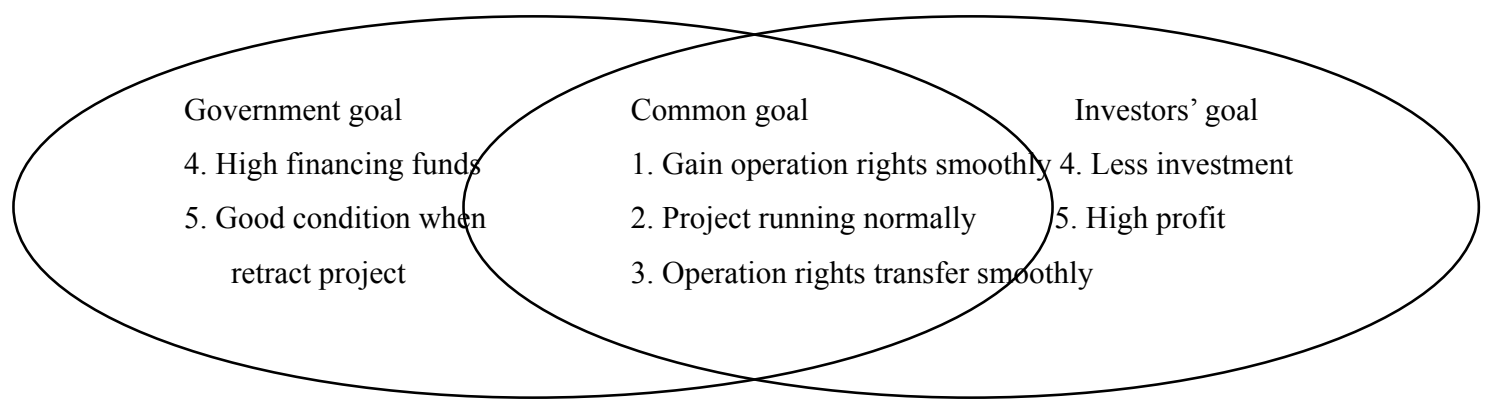

Figure 1 The intersection of goal between the government and investors in TOT mode

In TOT mode, it would not reach a bilateral cooperation, if the conditions like "to reach both goal" "rational participation" "reasonable distribution of benefit" and "effective consultation" can't be met. The formation of cooperation need these four conditions working together rather than individual one to have a effect. As is shown in Figure 2 .

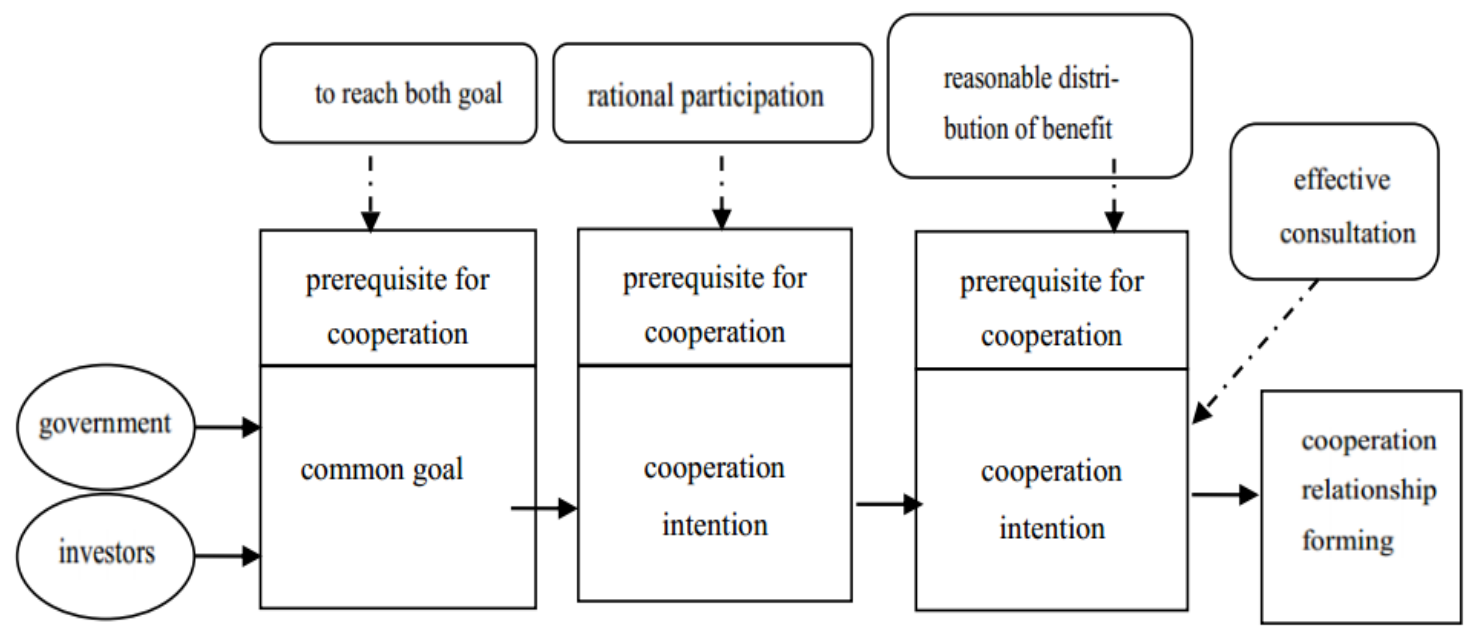

Figure 2 The formation of cooperation relationship between the government and investors

Basic settings for cooperation game between government and investors. Due to the restrictions of related laws and regulations, the transfer pricing of operation rights given by government must take account for the asset evaluation value given by a third-party evaluations institution accredited by relevant department. So the transfer price generally can't be lower than the 
asset evaluation value. Likewise, the investors also calculate expected return of the highway operation rights obtained by transfer. However, in the algorithm of the investor, the value of return rate is not fixed, but a value interval determined in consultation with government. Then the estimate price range of the investors with the reserve transfer price of government is regarded as a basis for transfer pricing, the two sides to conduct cooperative game on this basis ${ }^{[6]}$.

The total return obtained by cooperation should be allocated by both sides and the result of the game model is to determine the return allocated to each side. The total return obtained by cooperation is the difference between the pricing of the investors at the minimum acceptable return rate and the asset evaluation value given by evaluation institutions, while the return of the government is that the final transfer price exceeds the asset evaluation value given by evaluation institutions.

The return allocations of two-party cooperative game between the government and investors is denoted by $\Gamma\left(S, d, u_{1}, u_{2}\right)$, where $S$ is feasible distribution set, $d$ is breaking point, both $u_{1}$ and $u_{2}$ are the utility function of two sides in cooperative game. The different factors of two sides make it an asymmetrical cooperative game such as different standpoint, utility functions, etc.

Elements study of two-party cooperative game model. Feasible distribution set. In two-party cooperation game, the result of the game can't be decided directly by the individual tactics, because there is an agreement to control the game process. Thus the object of the agreement, namely the allocation solution of return is more important to each side of the cooperative game. Able to be allocated shows that only the subject that is easy to split can be as research object.

Utility function. In two-party cooperation game, another important concept is utility. The distribution return of each side are all expected return which has not been obtained, so risk factors of each side should be taken into consideration. The object of the game is sometimes non-cash return such as items, projects or resources, and sometimes cash return, but it can't reflect the return bringing to each side. Therefore, subjective utility also affects the distribution results of two sides. The inherent requirements and preferences of both sides are reflected by the utility, the utility configuration will influence the process and final results of two-party cooperation game through subjective attitude. In addition to considering the allocation $S=\left(s_{1}, s_{2}\right)$ of two-party cooperation game, it also needs to take account of the utility configuration $U=\left(u_{1}, u_{2}\right)$, where $u_{2}$ represents the expected utility of each side which is the function $u_{i}: S \rightarrow R$ from distribution set to the set of real numbers, that is the return function of both sides, namely $u_{i}=u_{i}(s)=u_{i}\left(s_{i}\right)$. Utility configuration set consists of all possible utility configurations, namely utility configurations is calculated through utility function from feasible distribution set.

Breaking point of negotiation. Breaking point of negotiation is also another important factor in two-party cooperation game. Breaking point of negotiation is the return they can obtain when negotiations rupture. Typically it is represented by $d=\left(d_{1}, d_{2}\right)$, where $d_{i}$ is the return they can obtain when negotiations rupture. Breaking point of negotiation is represented by $(0,0)$ when none of both sides to benefit. Breaking point of negotiation is also a subset of feasible solutions set. In other words, both sides of the game can choose breaking point of negotiation to terminate the agreement. 


\section{Transfer pricing model based on cooperative game}

Building the model. After the elements analysis of two-party cooperation game, we can build a model of two-party cooperation game to determine the project transfer pricing:

$$
\Gamma\left(S, d, u_{1}, u_{2}\right)
$$

Where $S$ represents distribution set of cooperation game, and

$$
S=\left\{\left(s_{1}, s_{2}\right) \mid s_{1} \geq 0, s_{2} \geq 0, s_{1}+s_{2} \leq q-P\right\}
$$

Breaking point of negotiation is:

$$
d=\left(d_{1}, d_{2}\right)=(P, 0)
$$

Utility configuration is:

$$
U=\left(u_{1}, u_{2}\right)=\left(P+s_{1}, s_{2}\right)
$$

Where $P$ represents asset evaluation value of operation rights given by a third-party evaluation:

$$
U=\left\{\left(u_{1}, u_{2}\right)\left\{u_{1} \geq d_{1}, u_{2} \geq d_{2}\right\}\right.
$$

Regardless of any negotiation game, the government and investors would adhere to that utility is not less than the breaking point of negotiation. Otherwise it would lead to rupture of the negotiations. Any solution to this return distribution of two-party cooperative game would be a subset of $U$.

Solving the game model between the government and investors in TOT mode. Using Robin Stein Bargaining game solution to solve the model, combined with the characteristics of highway operation rights in TOT mode, the following solving elements ${ }^{[7,8]}$ are defined:

$Y, y-$ Maximum or minimum return distribution proportion

Suppose the government first proposed profit distribution solution in TOT mode, the maximum return distribution proportion of the government is $Y_{1}$, the minimum return distribution proportion is $y_{1}$; the maximum return distribution proportion of the investors is $Y_{2}$, the minimum return distribution proportion is $y_{2}$.

$\chi$ - The intensity of the negotiation

The intensity of the negotiation between two sides in TOT mode is represented by $\chi_{1}, \chi_{2}$ respectively and $0 \leq \chi \leq 1$. The Size of the intensity of negotiations is determined by two-parties' individual factors, main factors such as risky sharing, the opportunity cost and the extent of the eagerness for the project to achieve, etc. When $\chi=0$, it Shows that the negotiators have lost all their patience and at this time, the game has becoming requirements with no room for negotiation; when $\chi=1$, it shows that patience is so adequate that there have been several stages of the game. The intensity of the negotiations is a manifestation of the ability of both sides in the game of bargaining, which refers to the ability of both sides of the game to get more return by way of negotiations of mutual bargaining in the course of the game. $V$ is project return available for distribution.

The total return available for distribution in TOT project is difference between the pricing of the investors at the minimum acceptable return rate and the asset evaluation value of the highway 
operation rights given by evaluation institutions, denoted by $V=q-P$.

The course of the game regarding to the return distribution proportion is shown in Figure 3.

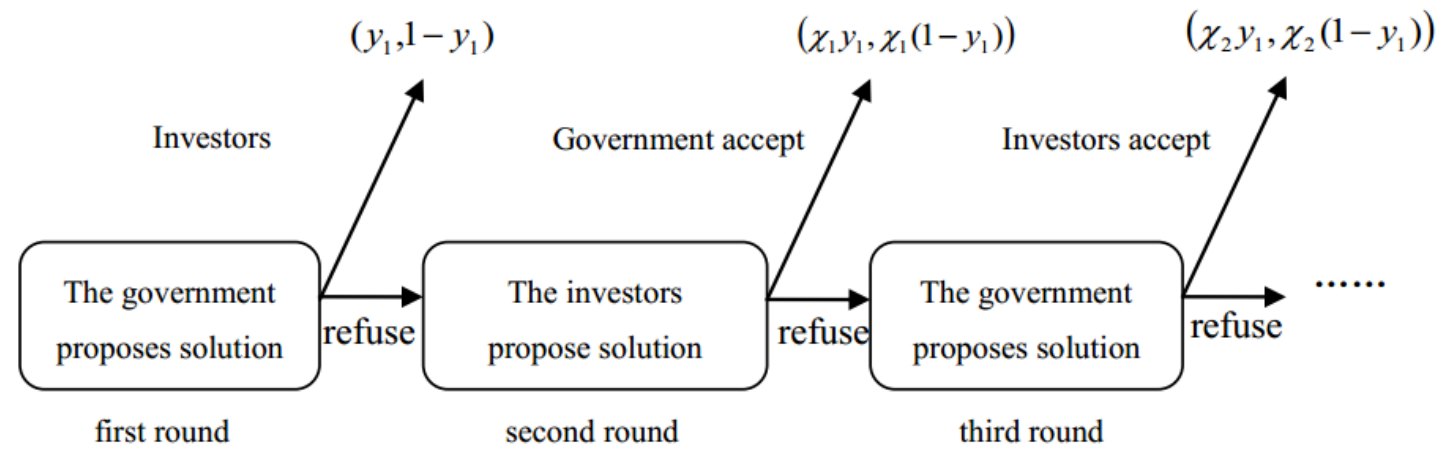

Figure 3 The course of the game between the government and investors in TOT mode

In the first round, the government took lead in proposing distribution solution in TOT mode, and in the allocation scheme, the government must maximize their proportion of return distribution on the premise that the proportion of the investors must at least be equal to proportion in the distribution of the second round. If the scheme of TOT project didn't appeal to investors, the investors would refuse and made their own programs, and the maximum return distribution proportion they could get was $\chi_{2} Y_{2}$, the minimum return distribution proportion was $\chi_{2} y_{2}$. Thus, the optimal proportion of return distribution in the first round should be between the minimum and maximum proportion of return distribution. In this case, the optimal allocation of the government was that the minimum and maximum return distribution is $1-\chi_{2} Y_{2}$ and $1-\chi_{2} y_{2}$ respectively. According to previous settings, the maximum and minimum return distribution proportion of the government of TOT project in the first round was $Y_{1}$ and $y_{1}$ respectively. Therefore, to get the following inequalities:

$$
\begin{aligned}
& Y_{1} \leq 1-\chi_{2} y_{2} \\
& y_{1} \geq 1-\chi_{2} Y_{2}
\end{aligned}
$$

In the second round, the investors of TOT project refused the distribution scheme proposed by the government, and proposed a reasonable distribution scheme by taking account of the situation of the government. If the government refused the return distribution scheme proposed by investors in the third round and gave its own scheme, the minimum and maximum proportion of return distribution which the government could achieve in the distribution is $\chi_{1} y_{1}$ and $\chi_{1} Y_{1}$ respectively. Thus, taking account of the distribution scheme which may be proposed by the government in the third round, the optimal proportion of return distribution of the government proposed by the investors in the second round should be between the minimum and maximum proportion of return distribution. In this case, the minimum and maximum proportion the investors could achieve in the distribution was $1-\chi_{1} Y_{1}$ and $1-\chi_{1} y_{1}$ respectively. Therefore, to get the following inequalities:

$$
\begin{aligned}
& Y_{2} \leq 1-\chi_{1} y_{1} \\
& y_{2} \geq 1-\chi_{1} Y_{1}
\end{aligned}
$$

Put (4) and (5) into (2) and (3) respectively to get the following two inequalities: 


$$
\begin{aligned}
& Y_{1} \leq \frac{1-\chi_{2}}{1-\chi_{1} \chi_{2}} \\
& y_{1} \leq \frac{1-\chi_{2}}{1-\chi_{1} \chi_{2}}
\end{aligned}
$$

By the analysis of (6) and (7), it can be concluded that in TOT projects the proportion of return distribution the government could get in the game was:

$$
Y_{1}=y_{1}=\frac{1-\chi_{2}}{1-\chi_{1} \chi_{2}}
$$

Thereby, the balance return gained by the government in TOT model projects was:

$$
s_{1}=\varphi_{1} V=\frac{1-\chi_{2}}{1-\chi_{1} \chi_{2}}(q-P)
$$

In this case, the balance return gained by the investors in TOT projects was:

$$
s_{2}=\varphi_{2} V=\frac{\chi_{2}\left(1-\chi_{1}\right)}{1-\chi_{1} \chi_{2}}(q-P)
$$

The return distribution between two sides in TOT projects is determined by the intensity of the negotiation $\chi$, when the value of transfer pricing $q$ of investors which is calculated at the minimum acceptable return rate and evaluation value $P$ of highway operation rights given by evaluation institutions are determined. The intensity of the negotiation is usually estimated by the contribution which participants made to the cooperative projects, namely the incremental benefit brought by participants in cooperative project. So the paper uses the proportion of the maximum utility of each side to the sum of the maximum utility of all to estimate the intensity of negotiations. Therefore, it is the one having larger intensity of the negotiation if the utility of the other having great room for growth. For this particular game, it has:

$$
\begin{gathered}
\chi_{1}=\frac{\max u_{2}}{\max u_{1}+\max u_{2}}=\frac{q-P}{q+q-P}=\frac{q-P}{2 q-P} \\
\chi_{2}=\frac{\max u_{1}}{\max u_{1}+\max u_{2}}=\frac{q}{q+q-P}=\frac{q}{2 q-P}
\end{gathered}
$$

Put(11)and (12) into (9)and (10) to get the expression:

$$
\begin{gathered}
s_{1}=\frac{2 q^{2}-3 q P+P^{2}}{3 q^{2}-3 q P+P^{2}}(q-P)=\frac{2 q^{3}-5 q^{2} P+4 q P^{2}-P^{3}}{3 q^{2}-3 q P+P^{2}} \\
s_{2}=\frac{q^{2}}{3 q^{2}-3 q P+P^{2}}(q-P)=\frac{q^{3}-q^{2} p}{3 q^{2}-3 q P+P^{2}}
\end{gathered}
$$

The final transfer pricing would also be determined by the return of two sides, denoted by $Q$ :

$$
Q=P+\mathrm{s}_{1}
$$

When the calculated result is in the feasible distribution set of the game, that is satisfying simultaneously with the requirements of $Q \geq d_{1}=P$ and $s_{2} \geq d_{2}=0$, the result meets the requirements. 


\section{Summary}

At the view of the application of TOT mode in highway project financing, the paper systematically analyzed the factor of price which had the most influence in process of TOT financing mode and built a model to determine transfer pricing combined with cooperative game theory, which leads transfer pricing to be more reasonable and scientific to be accepted by both sides.

\section{References}

[1] Wen Zhanbin. Discussion on the financing mode of TOT project in China [J]. Accounting Monthly, 2004, 4: 24-27

[2] Wang Liguo. Reflection on the use of BOT model to attract foreign investment[J]. China Investment, 2000, 1: 23-24

[3] Liu Xinmei, Wan Weiwu. Re-study of the economic property of infrastructure industrial[J]. Journal of Xi'an Jiao Tong University, 2000, 3: 35-37

[4] Liu Xinmei, LiangYing and Ai Genlin. The price decision model in TOT financing mode[J]. Journal of Xi'an Jiao Tong University, 2002, 4: 11-12

[5] Gao Hua. Research on the investment and construction contract of BT mode in China[D]. [Doctoral Dissertation of Tianjin University]. Tianjin: Tianjin University, 2009, 24-26

[6] Li Yongtao. The experimental economic test of bargaining theory. [J]. Business Studies, 2013, 3 : 25-26

[7] Dong Junjun. Study on the concession period of TOT project based on project risk assessment[J]. Project Management Technology, 2010, 12: 38-40[4]

[8] Zhao Hongyan. Study on the concession of BOT project [D]. [Doctoral Dissertation of Kunming University of Science and Technology]. Kunming: Kunming University of Science and Technology, 2004, 19-23 